UCRL-JC-125938

PREPRINT

\title{
Mapping Steam and Water Flow in Petroleum Reservoirs
}

M. Wilt, C. Schenkel, T. Daley, J. Peterson, E. Majer,

A.S. Murer, R.M. Johnston and L. Klonsky

This paper was prepared for submittal to the 1997 Society of Petroleum Engineers International Thermal Operations \& Heavy Oil Symposium Bakersfield, CA

February 10-12, 1997

November 1996

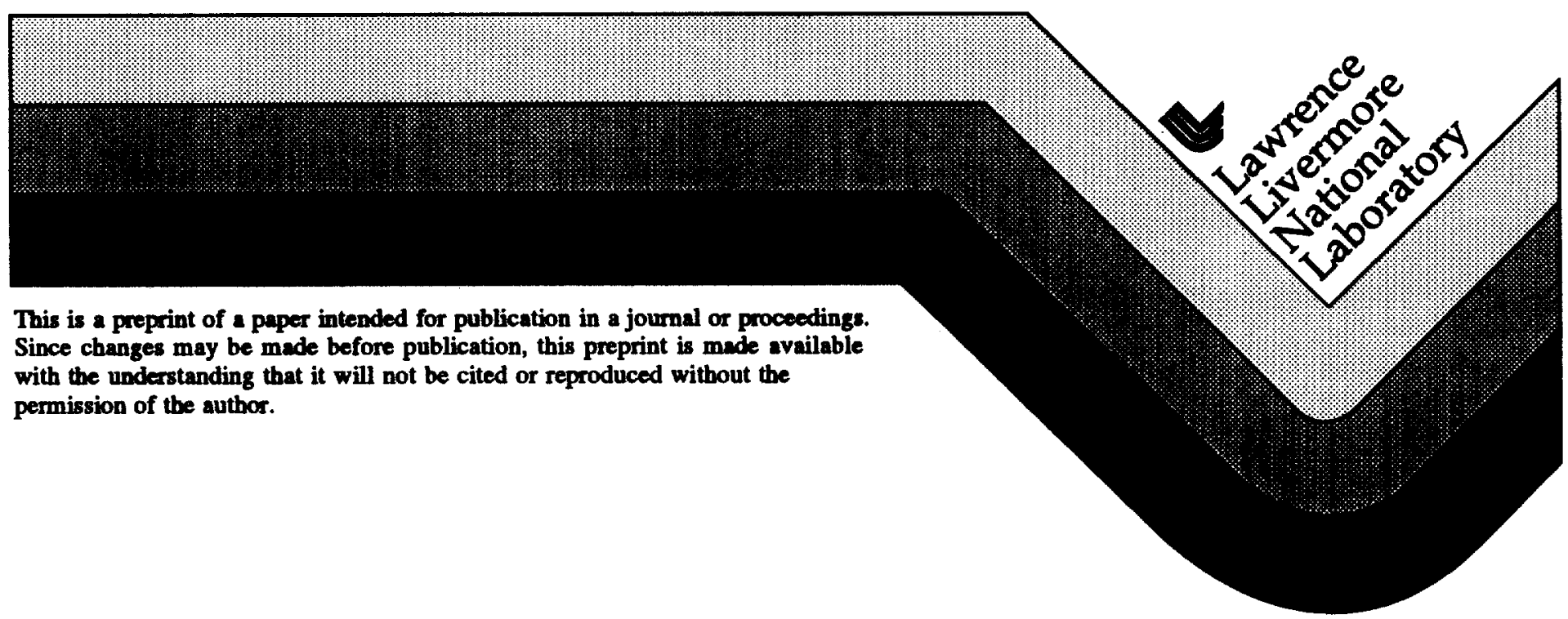




\section{DISCLAMER}

This document was prepared as an account of work sponsored by an agency of the United States Government. Neither the United States Government nor the University of California nor any of their employees, makes any warranty, express or implied, or assumes any legal liability or responsibility for the accuracy, completeness, or usefulness of any information, apparatus, product, or process disclosed, or represents that its use would not infringe privately owned rights. Reference herein to any specific commercial product, process, or service by trade name, trademark, manufacturer, or otherwise, does not necessarily constitute or imply its endorsement. recommendation, or favoring by the United States Government or the University of California. The views and opinions of authors expressed herein do not necessarily state or reflect those of the United States Government or the University of California, and shall not be used for advertising or product endorsement purposes. 


\title{
Mapping Steam and Water Flow in Petroleum Reservoirs
}

\author{
Michael Wilt and Clifford Schenkel, Lawrence Livermore National Laboratory; Tom Daley, John Peterson, and Ernest \\ Majer, Lawrence Berkeley National Laboratory; A.S. Murer, Mobil Exploration and Producing U.S.; R.M. Johnston, SPE, \\ CalResources LLC.; and Louis Klonsky, Chevron USA Production Co.
}

\begin{abstract}
This paper was prepared for presentation at the 1997 SPE Internationel Thermal Operalions Hoavy Oi Symposium, held in Bakerdield, Califomia, 10-12 February 1997.

This paper was selected lor presentation by an SPE Program Committee lollowing reviow of information contained in an sbetract submitted by the author(s). Contents of the paper, as presented, have not been reviowed by the Society of Petroleum Engineers and are abjoct to comection by the suthor(s). The materal, we presented, does not necesserlly reflect any position of the Society of Petroleum Encineen, he officers, or members. Papers precented at SPE meetinos are subject to publication review by Editorial Commitues of the Society of Pe Poroleum Engineers. Electronic reproduction, distibulon, or thoras of any part of this paper prommercia puposes without the wrtien concent of the socisty of Petroleum Engineers is prohibiled. Permission to reproduce in print is restricted to an abstract of not more than 300 words; Illustrations may not be copied. The abstract must contain conspleuous acknowedgment of where and by whom the papar was presented. Witte Librarian, SPE, P.O. Box 833836, Picthardson. TX 75063-3836, U.S.A., tax 01-972-952-9435.
\end{abstract}

\section{Abstract}

Over the past 5 years, we have applied high-resolution geophysical methods (crosswell seismic and electromagnetics (EM), and passive seismic) to map and characterize petroleum reservoirs in the San Joaquin Valley and to monitor changes during secondary recovery operations. The two techniques provide complementary information. Seismic data reveal the reservoir structure, whereas EM measurements are more sensitive to the pore fluid distribution.

Seismic surveys at the South Belridge field were used to map fracture generation and monitor formation changes due to the onset of steam flooding. Early results show possible sensitivity to changes in gas saturation caused by the steam flooding. Crosswell EM surveys were applied at a shallow pilot at Lost Hills for reservoir characterization and steamflood monitoring. Images made from baseline data clearly show the distribution of the target oil sands; repeated surveys during the steam flood allowed us to identify the boundaries of the steam chest and to accurately predict breakthrough. Applications of the EM techniques in steel-cased wells are at an early stage, but preliminary results at Lost Hills show sensitivity to formation resistivity in a water-flood pilot. Finally, passive seismic surveys during hydrofracture operations measured events correlatable in frequency content and magnitude with the size and orientation of induced fractures.

\section{Introduction}

Although large quantities of petroleum are produced through water and steam flooding, the process is typically poorly understood. This leads to inefficient recovery and associated production problems, such as premature water/steam breakthrough, fracturing of reservoir rock, and well failures. In a new effort to understand these fluid displacement processes and associated reservoir changes, we are applying crosswell geophysical methods to monitor secondary recovery processes.

The goal of this project is to jointly use high-resolution geophysical methods to map and characterize petroleum reservoirs during secondary recovery operations. We view the introduction of steam and water floods in petroleum reservoirs as natural tracers to map fluid flow and to define the reservoir structure. Efficient use of such tools can help us determine the flow mechanisms, map the creation and destruction of fracture porosity, and track the injected flow through natural channels that connect (and isolate) petroleum deposits. It is an ideal mechanism for detailed reservoir characterization; the reservoir is defined (and redefined) as it is produced.

In 1994, a partnership was formed between Lawrence Berkeley and Lawrence Livermore national laboratories (LBNL and LLNL) and a group of San Joaquin Valley oil producers including $\$$ CalResources, Chevron, Mobil, and independent Bakersfield Energy. The partners agreed to apply geophysical techniques to characterize several pilot areas and to monitor existing and incipient steam- and water-flood projects within the valley. The multiyear project consists of a series of geophysical surveys in several pilot areas and joint efforts to interpret the data in terms of reservoir properties and ir changes during oil production.

In this paper, we will briefly describe the technologies applied and examine some early field results from several of the pilot field projects.

\section{Geophysical Methods}

The two main geophysical tools employed are crosswell seismics and crosswell EM. These provide complementary 
high-resolution data on fundamental reservoir properties. Seismic measurements often reveal the reservoir structure and the location of fracture zones and bedding planes. EM data define the resistivity of the rock, which is in turn sensitive to the distribution of pore fluids. We apply these techniques to small- to moderate-scale field experiments, so we can improve our understanding of fluid flow during recovery. Data are collected in observation and production wells at depths encompassing the injection and production zones. We use core and log data to help interpret results.

In addition to these active source techniques, we also apply passive seismic monitoring to image fracture creation and growth during hydrofracturing and steam injection.

Crosswell EM System. The LLNL/LBNL crosshole EM system consists of separate transmitter and receiver stations that deploy tools in wells separated by up to several hundreds of meters (Fig. 1). The transmitter uses a vertical-axis magnetic core wrapped with 100 to 300 turns of wire and tuned to broadcast a low-frequency sinusoidal signal at frequencies from $100 \mathrm{~Hz}$ to $20 \mathrm{kHz}$.'

The transmitter signal induces electrical currents to flow in the formation between the wells. These currents in turn generate a secondary magnetic field in proportion to the electrical resistivity of the rock where they flow. By measuring the fields from the receiver borehole, we can infer the resistivity distribution between wells.

At the receiver borehole, a custom-designed coil detects the vertical magnetic field and sends it up the logging cable to a lock-in amplifier located at the surface. The lock-in amplifier operates like a radio by measuring only those signals that are coherent with the transmitted signal while rejecting incoherent background noise. An in-field computer is used to keep track of the transmitted signal, the detected magnetic field, and the depths of both source and receiver coils.

By positioning both the transmitter and receiver tools at various levels above, below, and within the zone of interest, we can create an image of the resistivity distribution between the wells. The EM data are interpreted by computer modeling in which the rock between the wells is divided into twodimensional, square blocks 1 to $5 \mathrm{~m}$ on a side. Each block is assigned an electrical resistivity value, estimated from the borehole resistivity $\log$ (if available). The computer then modifies the resistivity of these blocks until the calculated and measured EM data agree to within the measurement error, usually 1 to $2 \%$. This process usually requires 10 to 12 hours per dataset on a $50-\mathrm{MHz}$ workstation to produce a detailed image of the underground strata.

Crosswell Seismic System. The crosshole seismic system consists of a high-frequency piezoelectric source and borehole sensors. The receivers may be deployed in combination with the source for active experiments such as crosshole tomography or separately for passive listening during hydrofractures or reservoir injection.

The seismic source is a high-voltage piezoelectric transducer, which can be operated in a pulse mode or in a controlled signal sweep mode. It operates at frequencies up to $15000 \mathrm{~Hz}$ and is effective at well separations of $200 \mathrm{~m}$ or more, depending on the rock type. The high-frequency characteristics of this source make it ideal for resolving smallscale features such as fractures and injection fronts.

We deploy both hydrophones and three-component clamped geophones for signal detection. The hydrophone string is often used with the piezoelectric source in waterfilled boreholes; this tool deploys rapidly. The clamped geophones are typically used for passive monitoring where it is necessary to detect lower-level signals and obtain multicomponent data.

\section{Field Experiments}

Seismic and EM field projects were initiated as early as 1994 and continue in four separate field areas. Most projects are in early to intermediate stages of completion, but several have just begun secondary operations. In the following sections, we provide selected highlights from some of these.

Seismic Measurements at the CalResources Pilot, South Belridge Field. CalResources is presently applying a highenergy steam drive for oil recovery in diatomite reservoirs at the South Belridge field. This pilot is the third in a series to understand the steam-flow mechanism in this very tight rock. Previous results were generally encouraging for enhanced oil production, but there was evidence of steam bypass and breakthrough into intervals outside the targeted injection zone. $^{2}$

Well drilling for the third pilot began in April 1995. The new wells included two fiberglass and two steel-cased observation wells in addition to the injection and production wells in the 5/8-acre pilot. Because of the unexpected encounter of a hot zone within the overlying Tulare sands, both fiberglass wells were lost almost immediately after drilling. We were therefore unable to collect EM data for this site.

Three crosshole seismic surveys were completed: one immediately after the onset of steam in June 1995, the second in August 1995, and the third in February 1996. The initial survey included passive seismic monitoring during hydrofracturing. The results of this monitoring showed no observable activity. The lack of microseismicity was surprising in light of the high seismicity observed earlier in a different part of the field during steam injection.

Initial crosshole measurements showed strong attenuation of the $\mathrm{P}$-wave phase despite good energy in later arriving $\mathrm{S}$ 
waves. The weak $\mathrm{P}$-wave energy was quite surprising in view of strong P-wave energy during crosshole surveys at Mobil leases within the same field.

In the follow-up survey two months later, we had similar results - that is, weak P-wave energy but strong $S$ waves (Fig. 2a). The third survey, made six months after the steam injection had begun, had dramatically different results. In this case, the $P$ waves are noticeably stronger over much, but not all, of the recorded interval. This change clearly indicates that significant changes are occurring in the reservoir because of the steam flooding.

Although there are several possible explanations for this behavior, such as near-borehole changes in rock properties, we suspect that the cause may be reservoir pressurization. As reservoir pressure increases because of the steam flood, we expect a corresponding decrease in gas saturation, which in turn dramatically increases the seismic signal levels. The seismic data may therefore be a rough indicator of local reservoir pressurization. Notice also in Fig. 2 that the change is not uniform over the entire section. P-wave data at some levels are still quite small or missing, thereby indicating that the pressurization is not uniform.

Crosshole EM Measurements at Lost Hills. A series of crosshole EM surveys was conducted at Mobil Oil leases at Lost Hills in central California beginning in 1993. The measurements were made to demonstrate the technology for characterizing oil reservoirs and monitoring steam floods. Two fiberglass-cased boreholes were drilled about $55 \mathrm{~m}$ apart near a steam injector in shallow, heavy oil sands. Steam was injected at depths of 65,90 , and $120 \mathrm{~m}$, corresponding to upper, middle, and lower layers of the target Tulare formation. $^{3}$

The resulting crosshole EM induction images (Figs. 3a and 3b), collected before steaming and six months after, clearly show the distribution of the high-resistivity oil sands (dark gray) and the intervening shale layers (light gray) The arrows indicate points of steam injection. The image in Fig. 3a indicates that the upper oil sand is a thick unit dipping gently eastward. The middle and lower sands are thinner and more discontinuous between the wells. The image shown in Fig. 3b is visibly different only at depths below $70 \mathrm{~m}$, where the resistivity has decreased significantly as a result of the steam injection. In all other parts of the image, the before and after resistivity values are unchanged. The resistivity decline is caused by the temperature increase and the replacement of oil by water and steam.

Figure $3 c$ is a "difference" image made by subtracting the baseline image (Fig. 3a) from the monitoring image (Fig. 3b). This figure, which highlights the parts of the section that have changed during the steam flooding, shows that the resistivity has decreased dramatically in the middle and lower oil sands, indicating the presence of substantial steam there. The image also indicates that almost no steam has gone into the upper oil sand. In addition, Fig. 3c indicates that the steam preferentially flows to the west in the middle sand but to the east in the lower unit.

The EM surveys showed the steam flood to be much less uniform than the operator anticipated, providing valuable information on the progress of the flood and the parts of the reservoir affected by the steaming. In fact, our predictions have been confirmed by recent temperature and induction resistivity logs in fiberglass-cased observation wells. We continue to monitor the progress of this steam flood and are concentrating efforts on the upper oil sand.

Water Flood Monitoring with Crosshole EM in SteelCased Wells. Since most available boreholes in operating oil fields use steel casing, it is difficult to do crosswell EM surveys, because the casing causes a high attenuation and phase delay of the transmitted signal. Recent research suggests that, although difficult, it is possible to make effective crosswell measurements, even in steel wells. Extending the crosshole EM technique to steel-cased wells is an important objective of our research because it dramatically broadens the use of this technique.

In 1994, we began a collaborative project with Mobil to test the crosshole EM technique for mapping the resistivity structure between wells and to track resistivity changes due to the water injection. Fiberglass monitoring well 003 is located $10 \mathrm{~m}$ from a water injector and $90 \mathrm{~m}$ from a steel-cased production well. Induction resistivity logs in 003 show that the average resistivity of the diatomite is 2.5 to $3 \mathrm{ohm}-\mathrm{m}$, varying between 1.5 and $4 \mathrm{ohm}-\mathrm{m}$ in the production interval from 550 to $770 \mathrm{~m}$. In addition, repeat induction logs show that the water injection has decreased the resistivity from 20 to $40 \%$.

For the initial test, we positioned both source and receiver tools at the same vertical level and adjusted the frequency of the transmitter beginning at the lowest frequency detectable with our receiver $(20 \mathrm{~Hz})$. Then we increased the frequency until the signal was attenuated by the casing to below the section threshold (about $500 \mathrm{~Hz}$ ). These frequency soundings were made at 10 different levels, corresponding to different casing segments and small differences in formation resistivity. The sounding data were found to repeat over time to about $3 \%$.

In Fig. 4, we show a crosshole frequency sounding from a depth of $550 \mathrm{~m}$. The data are plotted with numerical calculations for steel-casing models with and without a 3 ohm$m$ formation. The casing parameters were obtained by using the Schlumberger METT casing evaluation log for the thickness and by trial-and-error fitting of the lower-frequency section ( $<50 \mathrm{~Hz}$ ) of the crosshole soundings to obtain the conductivity and magnetic permeability of the casing. At these lower frequencies, the calculated models with and without conducting formation effects agree to within a few percent. 
At frequencies above $50 \mathrm{~Hz}$, the effect of the formation causes the total response curve to deviate from the curve with the casing alone. The observed data seem to correspond much more closely to the model with the formation present. This promising result, coupled with other research, strongly suggests that the formation resistivity may be obtained with crosshole EM even in steel-cased wells.

In future surveys, our goal is obtain a complete tomographic resistivity section through one steel well casing. In addition, we expect that within a year or two, the ongoing EM monitoring will yield information on the subsurface resistivity changes due to water flooding.

Passive Monitoring Microseismic Activity at Lost Hills. In an experiment separately supported by Chevron, a two-stage fracture stimulation of the lower Diatomite formation at Lost Hills was monitored for microseismic activity. We used two monitoring wells, each located approximately $10 \mathrm{~m}$ from the injector. In one well, we deployed a clamped three-component geophone and in the other, a five-level string of hydrophones. The seismic data were recorded on a high-frequency system (bandwidth of $12 \mathrm{kHz}$ ).

The objective of this test was to collect data for use in designing a fracture and fracture-growth imaging experiment. In the future, test fractures will be imaged using low-cost hydrophones to monitor microseismic events.

Figure 5 is a histogram of events detected during the first stage of fracturing. A striking increase in the number of events is observed after the shut-in following the first stage of the fracturing. It is notable that the observed seismic events have a high-frequency content and that events of a similar size tend to cluster in time. We also observed that the average frequency of events was approximately $500 \mathrm{~Hz}$ with seismic energy observed up to $6000 \mathrm{~Hz}$. We can use this information to study the size and orientation of induced fractures. With only two observation wells, the location of these events is imprecise. Future deployment would use four or more observation wells.

\section{Discussion and Conclusions}

In this paper, we have shown geophysical data that relate to reservoir changes during steam and water flooding and during hydrofracturing operations. Although the projects are clearly at an early stage, the results indicate that the geophysical measurements may provide a diagnostic tool for monitoring reservoir behavior during secondary and tertiary operations. The next stage is to attempt to match these behaviors with known or suspected reservoir behavior during production.

\section{Acknowledgments}

This work was supported by Chevron USA and the U.S. Department of Energy, Assistant Secretary for Fossil Energy, Office of Oil and Gas Technology through the Natural Gas and Oil Technology Partnership Program at Lawrence Livermore National Laboratory and Lawrence Berkeley National Laboratory under Contract DE-AC03-76SF00098.

\section{References}

1. Wilt, M., Lee, K.H., Becker, A., Spies, B., and Wang, B.: "Crosshole EM in Steel-Cased Boreholes," Expanded Abstracts for the Society of Exploration Geophysicists Annual Meeting (1996), Denver, CO.

2. Kovscek, A.R., Johnson, R.M., and Patzek, T.W.: "Evaluation of Rock/Fracture Interactions during Steam Injection through Vertical Hydrofractures," paper SPE 29622 (1995).

3. Wilt, M., Lee, K., Alumbaugh, D., Morrison, H.F., Becker, A., Tseng, H.W., and Torres-Verdin, C.: "Crosshole Electromagnetic Tomography-A New Technology for Oil Field Characterization," The Leading Edge of Exploration, Society of Exploration Geophysicists (1995), pp. 173-177.

\section{SI Metric Conversion Factors

acre $\times 4.047 \quad E+03=m^{2}$ \\ $\mathrm{m} \times 3.281 \quad \mathrm{E}+00=\mathrm{ft}$} *This work was performed under the auspices of the U.S. Department of Energy
by Lawrence Livermore National Laboratory under contract No. W-7405-Eng-48. 


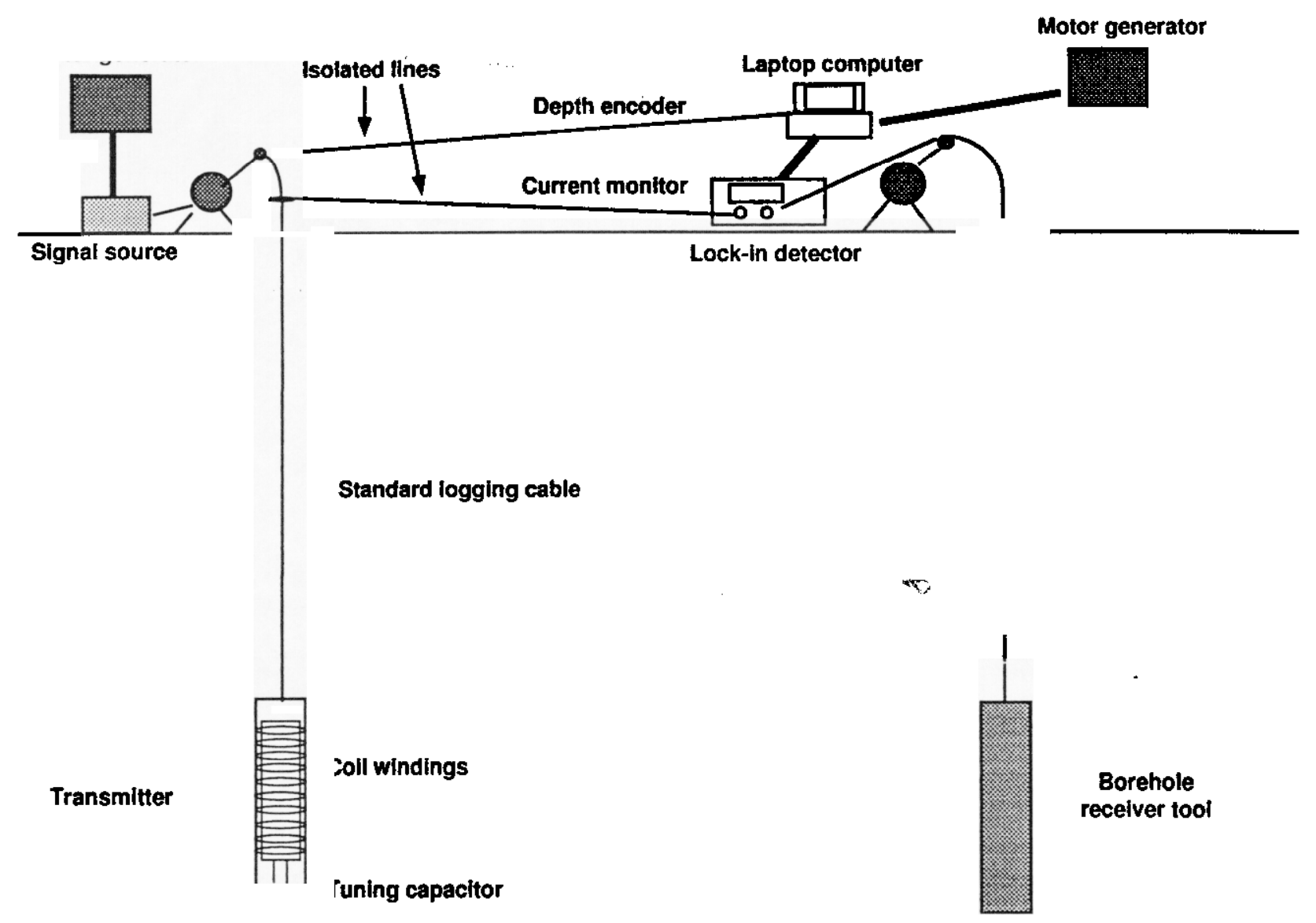

(a)

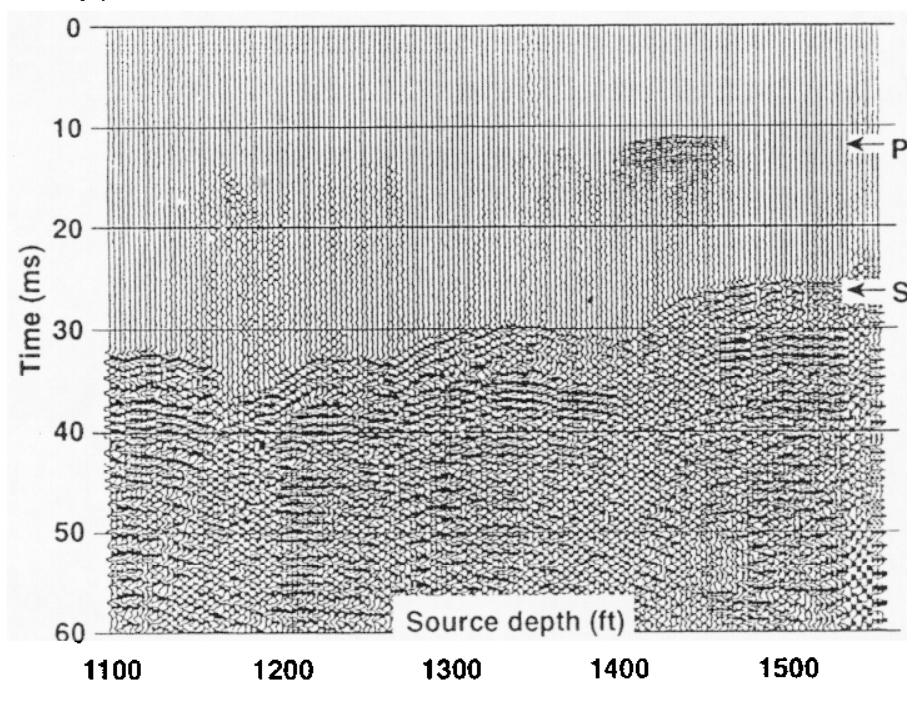

(b)

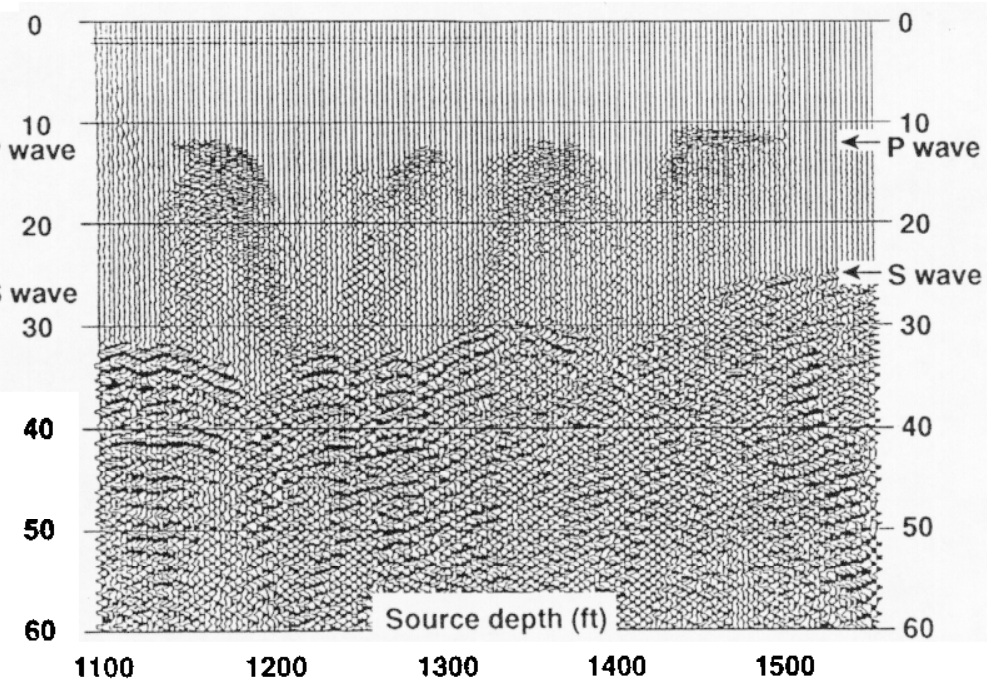

Fig. 2-Crosshole seismic recordings following the Initlation of a steam flood at the South Belridge field in July 1995 . (a) Data from the August 1995 survey show highly attenuated P-wave phase and strong S-wave energy. (b) Data from February 1996 show large increases in P-wave energy. This change is believed to be related to a decrease in gas saturation caused by reservoir pressurization. 
(a) Baseline $9 / 93$

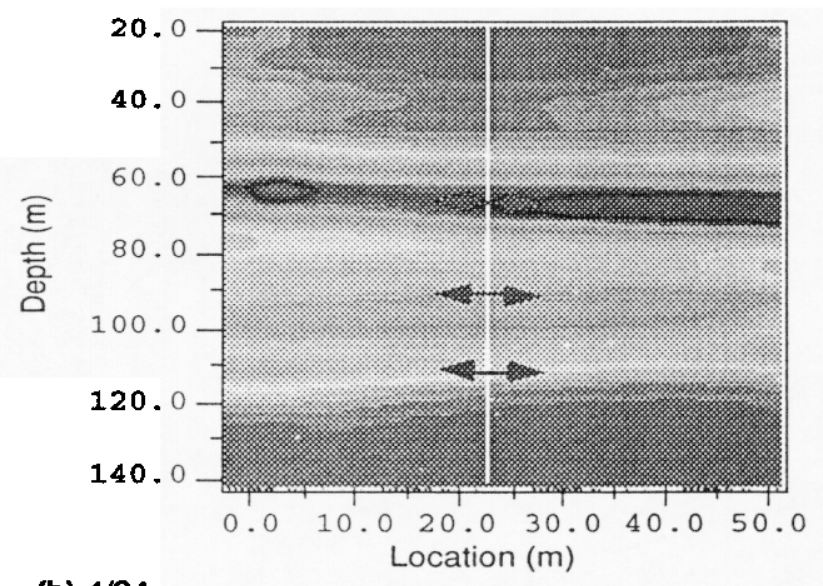

(b) $4 / 94$

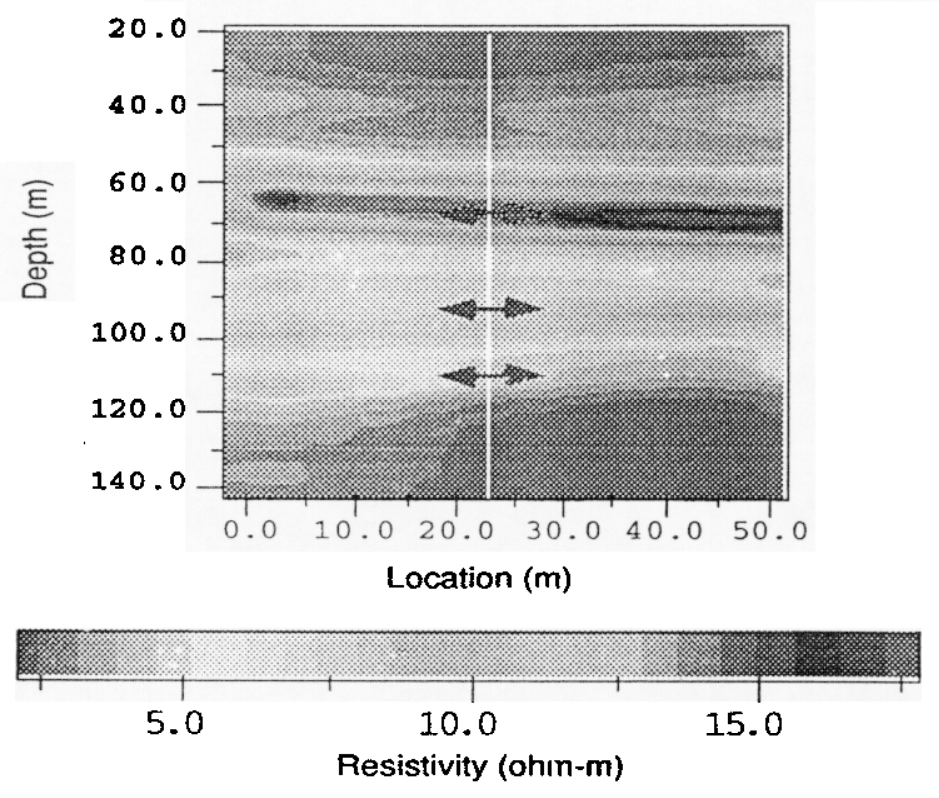

(c) Percent difference
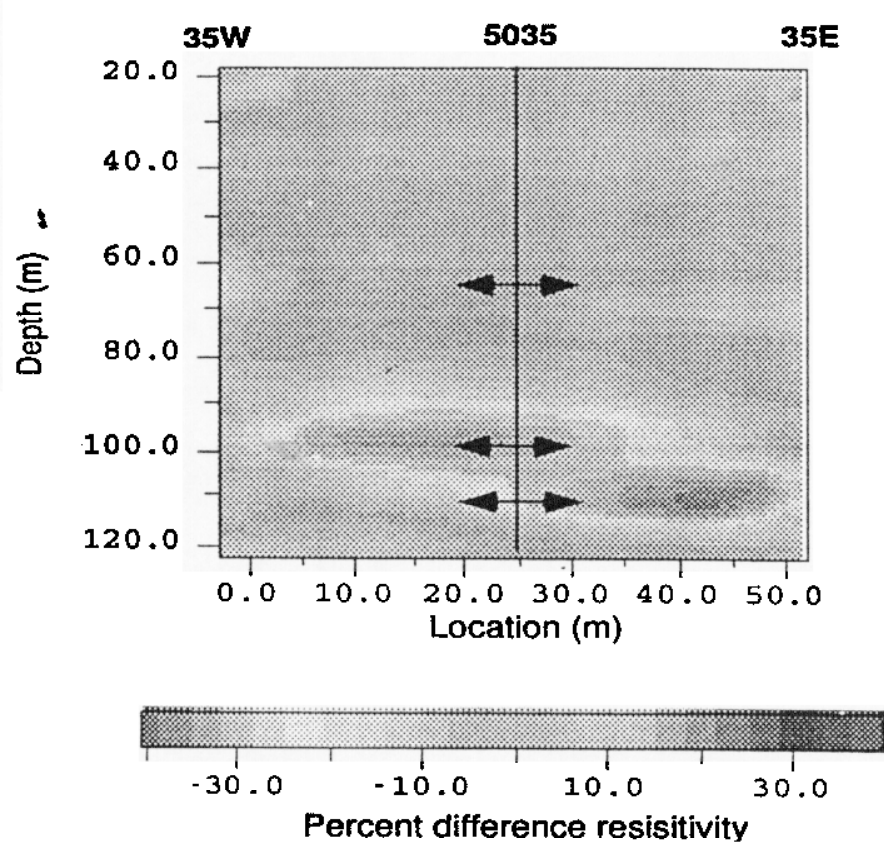

Fig. 3-Crosshole resistivity tomographic sectlons from Lost Hills 3 steam flood. (a) The baseline image maps the Oldisand distributions between wells. (b) The image after 6 months of steam flooding is similar to baseline results except at depths below $70 \mathrm{~m}$. (c) The difference image, made by subtracting (b) from (a), shows that the resistivity has decreased in the lower two target sands but has remained unchanged In the upper sand. 


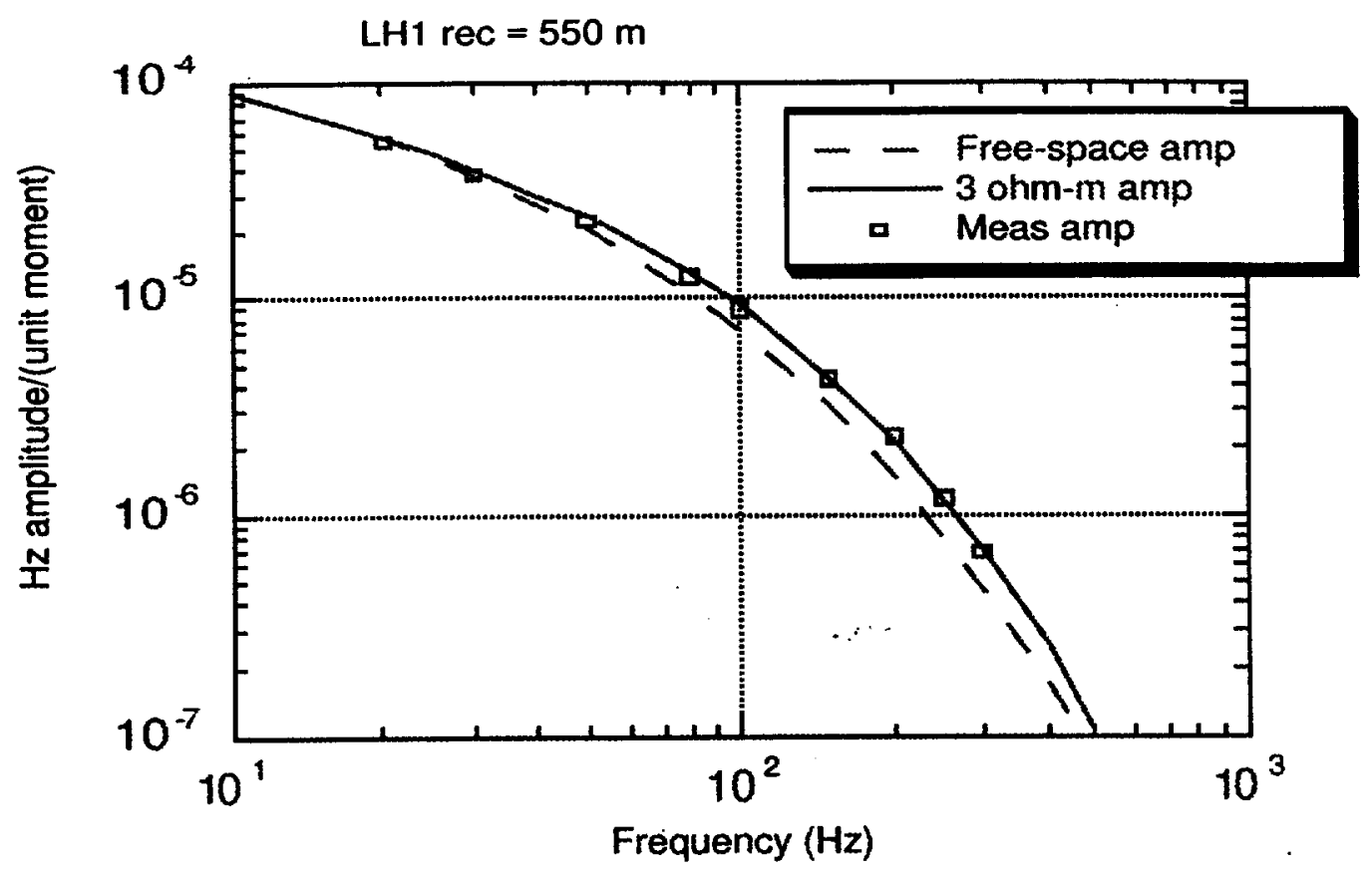

Casing prop thick $=1 \mathrm{~cm}(0.4 \mathrm{in}$.)

Cond $=3.6 \times 10^{6}$

Mag perm $=80$

Fig. 4-Crosshole EM sounding measurements through a steel-cased borehole at the Lost Hills field. The plot indicates that the collected data are consistent with a model that accounts for both the steel casing and the formation resistivity.

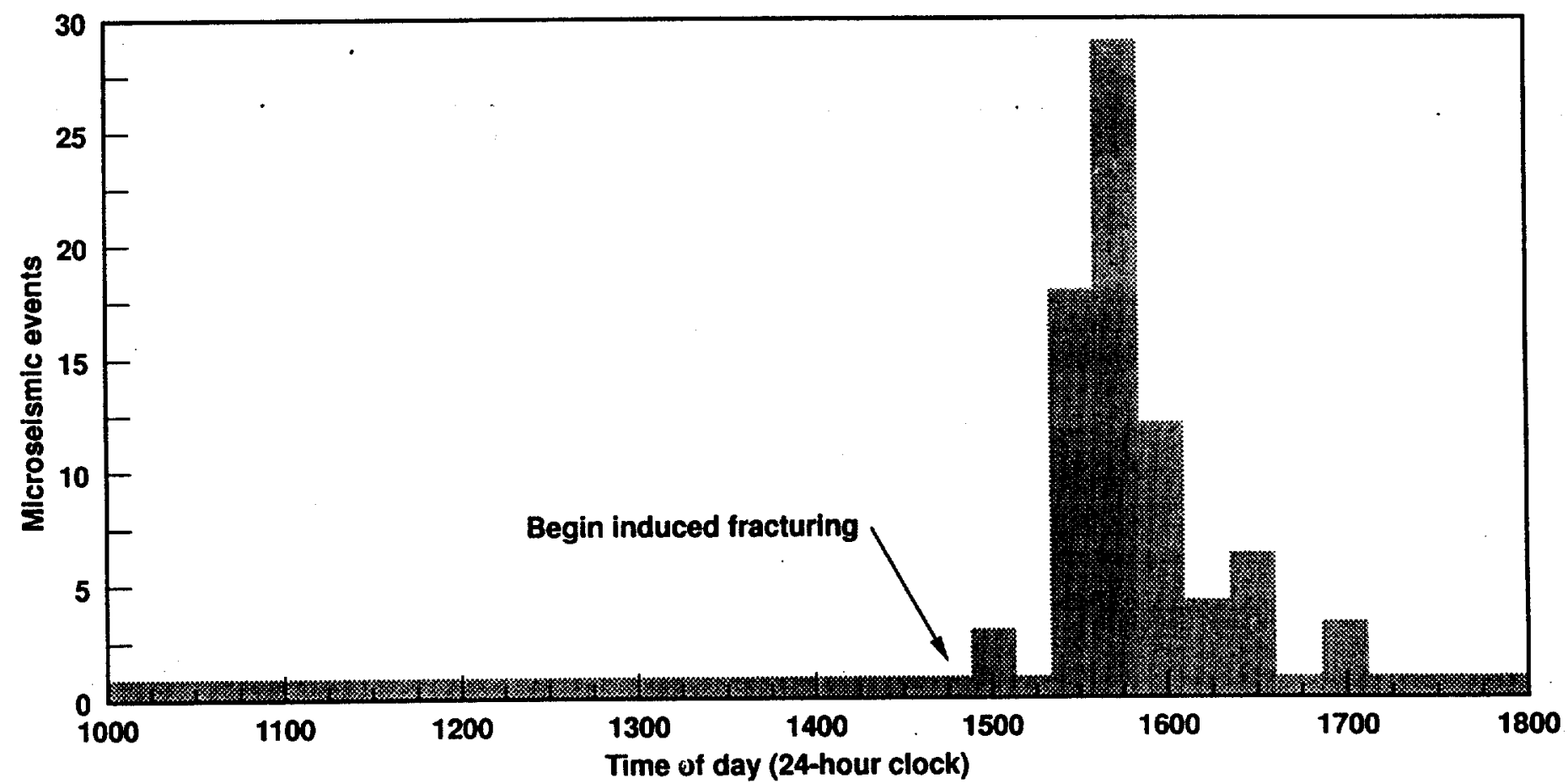

Fig. 5- Histogram of microseismic events recorded during a two-stage induced fracturing of diatomite at Lost Hills. Monitoring began during fracturing at 1000 hours, and no events were observed until several hours after fracturing was completed. At 1700 hours, the second stage tracturing was completed; this activity yielded no events. 


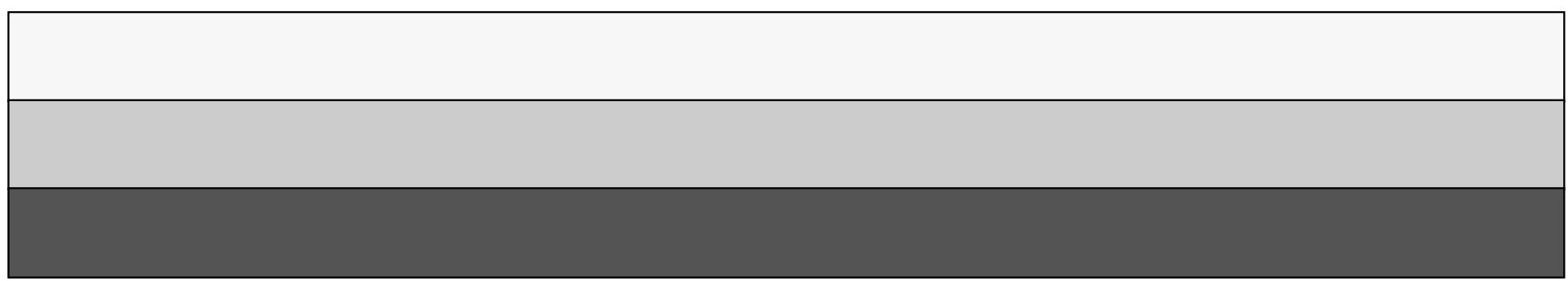

